Clemson University

TigerPrints

$9-2016$

Situating Computer Simulation Professional Development: Does It Promote Inquiry-Based Simulation Use?

Amanda L. Gonczi

Jennifer L. Maeng

Randy L. Bell

Brooke A. Whitworth

Follow this and additional works at: https://tigerprints.clemson.edu/teach_learn_pub

Part of the Science and Mathematics Education Commons 


\title{
Situating Computer Simulation Professional Development: Does It Promote Inquiry-Based Simulation Use?
}

\author{
Amanda L. Gonczi, Jennifer L. Maeng, Randy L. Bell \& Brooke A. Whitworth
}

To cite this article: Amanda L. Gonczi, Jennifer L. Maeng, Randy L. Bell \& Brooke A. Whitworth (2016) Situating Computer Simulation Professional Development: Does It Promote Inquiry-Based Simulation Use?, Computers in the Schools, 33:3, 133-152, DOI: 10.1080/07380569.2016.1205351

To link to this article: http://dx.doi.org/10.1080/07380569.2016.1205351

Published online: 15 Sep 2016.

Submit your article to this journal $\sqsubset$

ai

View related articles $₫$

View Crossmark data ¿ 


\title{
Situating Computer Simulation Professional Development: Does It Promote Inquiry-Based Simulation Use?
}

\author{
Amanda L. Gonczi ${ }^{a}$, Jennifer L. Maeng ${ }^{a}$, Randy L. Bell ${ }^{b}$, and Brooke A. Whitworth \\ a University of Virginia, Charlottesville, Virginia, USA; ${ }^{\mathrm{b}}$ Oregon State University, Corvallis, Oregon, USA; \\ 'Northern Arizona State University, Flagstaff, Arizona, USA
}

\begin{abstract}
This mixed-methods study sought to identify professional development implementation variables that may influence participant (a) adoption of simulations, and (b) use for inquiry-based science instruction. Two groups (Cohort 1, $N=52$; Cohort 2, $N=$ 104) received different professional development. Cohort 1 was focused on Web site use mechanics. Cohort 2 was situated in nature and provided three additional elements: (a) modeling simulation use within inquiry-based instruction; (b) collaboration; and (c) provision of content-relevant lesson planning time. There was no difference in the extent of simulation use between cohorts, $\chi^{2}(1)=0.878, p=.349, \phi=-0.075$. Results were inconclusive for a difference in observed inquiry instruction as Fisher's Exact Test was insignificant but had a medium effect size, $p=.228$, $\phi=0.283$. Computer-based standardized tests emerged as a novel technology integration barrier. These findings have implications for school policy, professional development, and future research.
\end{abstract}

\section{KEYWORDS}

Professional development; simulations; elementary science; situated learning theory

Although educational technology (ET) is increasingly expected to be a component of science curricula, many teachers do not readily adopt new technologies (Higgins \& Spitulnik, 2008; Zhao \& Bryant, 2006). Teachers may be resistant to ET use because of a lack of comfort with the technology (Russell \& Bradley, 1997), a perceived conflict between available time and ET integration (Jimoyiannis, 2010; Pennell \& Ewing-Taylor, 2012), or because they do not believe the ET will augment their curriculum (Higgins \& Spitulnik, 2008). As a result, there is an emphasis on providing science teachers with professional development (PD) that increases their familiarity with emerging technologies and their importance in science education (President's Council of Advisors on Science and Technology, 2010).

Simulations are one potential ET benefit and science teachers are increasingly encouraged to utilize them (Hilton \& Honey, 2011). Evidence supporting the benefits of simulations is growing (Dega, Kriek, \& Mogese, 2013; Hilton \& Honey, 2011; Plass et al., 2012). However, it is also clear that effective simulation use is more complicated than simple integration (Marshall \& Young, 2006; Hennessy et al., 2007).

CONTACT Amanda L.Gonczi alg3cb@virginia.edu EDepartment of Curriculum, Instruction, \& Special Education, Curry School of Education, University of Virginia, 405 Emmet Street, P. O. Box 400273, Charlottesville, VA 22904, USA. 
For example, simulations need to be integrated within an inquiry-based science curriculum to support maximum student achievement and interest in science (Chang \& Linn, 2013; Walker et al., 2012). Given the potential advantages of simulations, PD variables that increase participants' simulation adoption and use for inquiry instruction need to be clarified with studies that include comparison groups (Lawless \& Pellegrino, 2007; Luft \& Hewson, 2014). The present study specifically sought to examine whether simulation PD that included situated elements (situated PD [SPD]; modeling, collaboration, and practice) resulted in higher participant adoption of simulations and use for inquiry-based instruction than a comparison PD without these elements (technical PD [TPD]). The specific research questions addressed in the study included:

1. To what extent did participants in the TPD and SPD implement simulations into their science instruction?

2. What factors hindered simulation implementation for participants in the SPD?

3. To what extent did participants in each PD program use simulations for inquiry-based instruction?

\section{Computer simulations}

Simulations are virtual models that allow students to investigate and visualize scientific phenomena (Hilton \& Honey, 2011). Astronomers, physicists, chemists, and biologists regularly use simulations for working models and as a means for data collection (Medina \& Mauk, 2000; Nada \& Furakawa, 2012). Therefore, when teachers incorporate simulations into science instruction they provide students opportunities to work like scientists. In addition, students can use simulations to observe microscopic and macroscopic phenomena critical to improving student understanding of these concepts (Plass et al., 2012; Pyatt \& Sims, 2012; Ryoo \& Linn, 2012). For example, simulations allow students to observe molecular movement at various temperatures (Chang \& Linn, 2013), energy transfer during photosynthesis (Ryoo \& Linn, 2012), moon phases and planetary motion (Bell \& Trundle, 2008; Trundle \& Bell, 2010), and electric current flow (Finkelstein et al., 2005; Zacharia, 2007).

Research demonstrates greater conceptual learning when simulations are used for inquiry-based learning (Chang \& Linn, 2013; Dega, Kriek, \& Mogese, 2013; Donnelly, Linn, \& Ludvigsen, 2014). Trundle and Bell (2010) partly attributed greater gains in treatment participants' moon phase conceptual understanding to inquirybased simulation use. Treatment participants used the simulation to make predictions, collect data, and test hypotheses related to moon phases. As a result, participants in the treatment group may have been able to use the simulation to make greater gains in conceptual understanding compared with the control group that did not use the simulation.

Although simulation research increasingly demonstrates the value of simulations in science instruction, not all results have been positive (Marshall \& Young, 2006; Podolefsky, Perkins, \& Adams, 2010; Pyatt \& Sims, 2012). Inconsistent outcomes 
may be attributed to "aspects of instruction, pedagogy, teacher effectiveness, subject matter, ability level, fidelity of technology implementation, and possibly other factors that may represent more powerful influences on effect sizes than the nature of the technology intervention" (Tamim et al., 2011, p. 17). Although there are many confounding variables, there is general agreement that inquiry-based simulation use can enhance student achievement and interest in science (Trundle \& Bell, 2010; Gibson \& Chase, 2002; Marshall \& Young, 2006). Unfortunately, teachers often use simulations for teacher-centered instruction rather than student-driven inquiry (Waight \& Abd-El-Khalick, 2007). As a result, PD variables that increase participants' inquiry-based simulation use, and possible integration barriers, need to be clarified (Hilton \& Honey, 2011).

\section{Instructional technology PD}

Studies that have examined teachers following technology-related PD indicate that several factors may facilitate changes in classroom practice and student achievement (Gerard et al., 2011; Guzey \& Roehrig, 2009). Gerard et al. (2011) reviewed 43 studies and found science teachers were more likely to implement ET when they had opportunities to collaborate with peers. In addition, participants were more likely to use ET for reform-based teaching, such as inquiry instruction, when they had access to pre-existing inquiry-based lesson plans and materials from which to work.

Although the findings of Gerard and colleagues (2011) can be used to guide technology-related PD implementation, the generalized ET PD research that informed their conclusions did not take into consideration unique characteristics of simulations that may influence classroom integration. For example, in a cross case study with four secondary teachers, the participants reported disparate student engagement when various ET types were integrated into science lessons (Guzey \& Roehrig, 2009). In addition, the teachers demonstrated unique preferences for and challenges incorporating certain ET, especially simulations (Guzey \& Roehrig, 2009). These findings indicate that different ETs may warrant unique PD features to enable successful classroom implementation and student engagement.

\section{Situated learning theory}

Learning is a process of information transfer often mediated by a social context (Brown, Collins, \& Duguid, 1989). In fact, the context not only shapes what is learned, but can either facilitate or hinder learning (Lave \& Wenger, 1991). For example, a learning environment that includes individuals with varying skill mastery levels provides less-skilled individuals models from which to learn (Lave \& Wenger, 1991). In addition, when a learner has opportunities to practice new skills in a realistic context under the supervision of more skilled individuals, there is a greater likelihood the learner will attempt to independently use and adopt new behaviors including instructional strategies (Lave \& Wenger, 1991). Conversely, when a context does not provide opportunities for collaboration and individual practice, 
it is unlikely learners will develop new skills on their own (Lave \& Wenger, 1991). Socially mediated learning helps perpetuate cultures and skills as novices learn from and ultimately replace the masters (Lave \& Wenger, 1991). In summary, learning is a social endeavor fostered by modeling, scaffolding, practice, and a realistic context (Brown et al., 1989; Lave \& Wenger, 1991).

Teacher PD should occur within contexts that promote learning and changes in teachers' practices as described by situated learning theory (Lave \& Wenger, 1991). This is especially true for ET PD since many teachers are reticent to use emerging technologies (Russell \& Bradley, 1997). Situated learning theory suggests that changes in teachers' practices will be more likely to occur when ET use is modeled, teachers are given multiple opportunities to practice using ET with scaffolded support from PD implementers, and when the PD context reflects an authentic learning environment teachers can relate to and envision themselves in (Lave \& Wenger, 1991).

Previous research indicates teachers have difficulty using ET to engage students in actual scientific behavior (Graham et al., 2009; Hennessy, Deaney, \& Ruthven, 2006; Waight \& Abd-El-Khalick, 2007). Instead, teachers are more likely to incorporate technology into teacher-centered, content-focused lessons (Graham et al., 2009; Waight \& Abd-El-Khalick, 2007). However, when simulations were modeled for inquiry-based instruction during pre-service science teachers' methods classes, the teachers commonly integrated simulations into student-centered lessons during their own student teaching (Bell, Maeng, \& Binns, 2013; Maeng, Mulvey, Smetana, \& Bell, 2013). The extent to which this is also true for in-service teachers is unknown, but it is possible modeling inquiry-based use during simulation PD may encourage desirable simulation use in more student-centered lessons (Brown et al., 1989; Ketelhut \& Schifter, 2011; Lave \& Wenger 1991).

Practice is another factor influencing skill acquisition and teachers' subsequent instruction following PD (Lave \& Wenger, 1991; Meskill, Mossop, DiAngelo, \& Pasquale, 2002; Morrison, 2013). Practice is desirable because it fosters automaticity and psychological ease, which can allow teachers to focus on the process of teaching rather than classroom management (Berliner, 2001). Increased automaticity may help accomplish two simulation PD goals: (a) teachers will be more likely to incorporate simulations into their own science instruction, and (b) teachers may be more likely to use simulations for inquiry-based instruction since the teacher's cognitive energy does not need to be devoted to technical simulation use details. Meskill et al. (2002) found distinct differences between novice and more experienced teachers regarding their ET beliefs and implementation patterns. Teachers with less ET experience attributed student learning to technological tools, used technology as a mechanism for rewarding or punishing students, and emphasized product completion. On the other hand, teachers with more ET experience perceived technology as empowering and facilitating a student-driven learning process. These research findings support the use of situated learning theory to explore PD outcomes and suggest that when teachers become learners during $\mathrm{PD}$, they need opportunities for 
practice so they can increase their comfort using new tools, reflect, and refine new instructional practices (Lave \& Wenger, 1991).

\section{Rationale}

Given the potential value of simulation use, research is warranted to identify PD elements that not only increase the number of teachers who incorporate simulations into science instruction but also increase their use for inquiry-based instruction (Hilton \& Honey, 2011). Prior studies have documented that while teachers may adopt ETs following PD, they do not embed them within inquiry-based instruction leading to limited instructional benefits (Waight \& Abd-El-Khalick, 2007). Donnelly et al. (2014, p. 592) argued, "Better technology integration and more effective professional development is needed to increase the number of students who benefit from these technologies." This study sought to clarify effective simulation PD elements within a control/treatment study design.

These considerations guided the investigation to compare elementary teachers' simulation use following two PD programs. In one program, situated learning theory was not considered during design and implementation (TPD). In the second program, implementers modeled desirable simulation use within an authentic inquiry context and provided opportunities for participants to practice using simulations and designing lessons that incorporated simulations (SPD). Collaboration was embedded in the SPD as participants worked together as inquiry-based learners during the implementer modeled lesson in addition to collaborative lesson planning. It was hypothesized that a greater percentage of participants in the SPD would use simulations during their science instruction due to greater opportunities for practice. In addition, as a result of implementer modeling, a greater percentage of participants from the SPD were expected to use simulations within scientific inquiry contexts. These variables have not been investigated within simulation PD, to the authors' knowledge, with a study design that includes a comparison group.

\section{Methodology}

This explanatory mixed-methods study used a variety of qualitative and quantitative sources. The research design reflects the methodological stance that PD quality can be inferred from observed patterns in participant teaching following the PDbut only to a certain extent. Self-report survey and interview data were additional sources used to help explain patterns in the observational data. A description of the context, data sources, and analytic methods follow.

\section{Context}

The participants in this study were part of a broader statewide science PD program that aimed to support the development of elementary science teachers understanding and inclusion of student-centered teaching methods (for a full description see Gonczi, 2015). The PD encouraged ET use to support students' technological and 
scientific literacy as well as engagement in scientific inquiry (International Society for Technology in Education [ISTE], 2008; National Research Council [NRC], 2012). To foster technology integration, participants received simulation PD as described in what follows.

\section{Participants}

Participants included all elementary participants during the first $(N=52)$ and second $(N=104)$ PD implementations. Participants had prior teaching experience that spanned 0 to 38 years and averaged 9.8 years.

\section{Treatment}

The intervention was a PD module intended to increase instructional use of simulations. To encourage simulation use, ExploreLearning ${ }^{\circledR}$ provided participants accounts that gave access to their commercial simulations (Gizmos ${ }^{\circledR}$ ) and supporting instructional materials. However, during the simulation PD module participants were also told about other free computer simulations, including Physics Educational Technology's (PhET) (https://www.phet.colorado.edu). To determine whether (a) implementer modeling, (b) collaboration, and (c) practice (lesson planning) opportunities might influence (a) simulation adoption, and (b) simulation use for inquiry instruction, the PD for Cohort 1 and 2 differed in key points.

\section{TPD}

During Cohort 1's PD, implementers introduced participants to simulations and focused on aspects of technical use. The following vignette (pseudonyms used throughout paper) reflects the module at one of the sites and is typical of that at the other sites.

\section{Technical simulation module}

The simulation module implementer, Lisa, displayed the ExploreLearning ${ }^{\circledR}$ Web site on a projection screen in the front of the room. She showed an introductory video that highlighted some benefits of simulation use. Each participant was given his or her own login and password and subsequently given about 10 minutes to set up his or her account. Lisa demonstrated how to set up classes, add students to rosters, and browse Gizmos ${ }^{\circledR}$ by content area and state standards. Lisa highlighted some Gizmo $^{\circledR}$ affordances including the ability to manipulate variables and take screen shots. Lisa pointed out how Gizmos ${ }^{\circledR}$ have accompanying curriculum materials including Student Exploration Worksheets and Teacher Guides. Each participant was given an ExploreLearning ${ }^{\circledR}$ Quickstart Guide that overviews many aspects of Web site use. Following this hour-long introduction participants were given time to browse Gizmos ${ }^{\circledR}$. During this time, participants often talked and shared interesting simulations they found that colleagues might also find useful (Observation, U1). 
Participants in the TPD were shown how to find simulations for certain content areas, how to access and modify ExploreLearning's ${ }^{\circledR}$ instructional materials, and how to interact with simulations. In addition, Lisa gave participants time to browse available simulations and consider how they could be incorporated into their own instruction. The TPD module lasted approximately two and a half hours and occurred in one session.

\section{SPD}

Cohort 2 participants spent less time on technical Web site use and had less time for simulation browsing. Instead, implementers modeled inquiry instruction using a simulation and incorporated content-relevant lesson planning time (practice) and opportunities for participants to show peers (collaboration and practice) their planned lesson as described in the exemplar below.

\section{Situated simulation module}

The implementer, Abbie, told the participants that the goal of the 3.5-hour PD session was to make sure, "By the end of the afternoon you will be comfortable with Gizmos ${ }^{\circledR}$." Next, Abbie introduced participants to Gizmos ${ }^{\circledR}$ by showing a PowerPoint ${ }^{\mathrm{TM}}$ and brief film about the product. Following the introduction, participants learned how to set up classes, add students and Gizmos ${ }^{\circledR}$ to classes, and other technical aspects of Web site use. Abbie then projected the photosynthesis Gizmo ${ }^{\circledR}$ on a SmartBoard ${ }^{\mathrm{TM}}$ and had participants brainstorm variables that might affect plant growth. Ultimately, participants tested their hypotheses and shared results with the whole group on chart paper. In addition, participants were given time to browse available Gizmos ${ }^{\circledR}$, to work collaboratively to develop a content relevant lesson incorporating a Gizmo ${ }^{\circledR}$, and to share lesson plan ideas with the whole group.

During the SPD participants were provided the same technical Web site information as in the TPD. However, the SPD also incorporated a modeled inquiry lesson and provided opportunities for greater participant collaboration and actual practice in designing and presenting their own lesson idea.

\section{Data sources and analysis}

Data sources included PD observations, pre-, post-, and delayed-post perceptions surveys, participant interviews, classroom observations, and observation reports. Data were preliminarily analyzed as collected, either sequentially or concurrently.

\section{PD observations}

The simulation PD at all three implementation sites was observed and field notes taken during both years of the study. Observation notes captured PD implementation and participant experiences. During these observations, evidence of effective 
simulation PD elements, informed by situated learning theory, was of particular interest (i.e., modeling within inquiry-based instruction, opportunities for lesson planning, and collaboration with peers and implementers.) Write-ups of each PD module were completed and coded for these situated elements to ensure fidelity in implementation across sites within a cohort and to document the differences between TPD and SPD.

\section{Perceptions surveys}

Participants completed perception surveys electronically pre-/post-/delayed-post PD. These surveys used Likert questions to identify whether participants had incorporated simulations into science instruction and their confidence in use. In order to attribute potential changes in participants' simulation use to PD elements, baseline frequency and confidence in simulation use were assessed on pre-perceptions surveys using a 5-point Likert scale question. An additional question was added to the Cohort 2 delayed-post perception survey to identify potential barriers to simulation implementation. This question was added to the survey after Cohort 1 interview data revealed integration barriers. Open-ended survey responses describing integration barriers were emergently coded. Emergent barrier codes reflected a common response from at least two participants. Three qualitative and science education researchers established face and content validity for the surveys.

\section{Interviews}

Two TPD and three SPD participants were interviewed using the validated protocol in Appendix A. Interview questions were designed to gather information about how participants incorporated simulations into their science instruction and their satisfaction with the PD. Interviews also documented personal experiences and contextual and/or personal factors that may have influenced simulation use patterns beyond the PD program. Three experts in qualitative and science education research reviewed the interview protocol to establish face and content validity. Participants were chosen for interviews based upon evidence of simulation use in observation reports. These semi-structured interviews lasted approximately 30 minutes and were audiotaped and transcribed for analysis. During analysis, the interviews were coded for evidence of inquiry-based simulation use, barriers to simulation implementation, and PD satisfaction.

\section{Observation reports}

Observation reports recorded instructional elements during an observed class period and three classes prior to and following the observed class to provide context (Appendix B). Participants completed observation reports at the same time as their videotaped lesson. Thus, participants completed four observation reports. Participants were assigned binomial codes to describe evidence of simulation use on 
observation reports to facilitate data analysis (Hesse-Biber, 2010) $(1=$ sim use, 0 $=$ no sim use). A two-way contingency table analysis was conducted to determine whether observation reports from the SPD and TPD participants were equally likely to include simulation use. The two variables were PD type (TPD, SPD) and the presence of simulations (yes, no). In addition, observation reports were analyzed to identify videos with simulation use for further analysis.

\section{Classroom observations}

Participants were observed and videotaped teaching science four different times during the academic year. Simulation implementation was observed in 10 Cohort 1 lessons and 16 Cohort 2 lessons. The first author took field-notes and completed write-ups of all videotaped lessons demonstrating simulation use. The videos were coded for evidence students engaged in inquiry-based learning (students using data to answer a research question through data analysis Bell \& Binns, 2005). Lessons that reflected inquiry-based simulation use were assigned a value of "1." Lessons that were not inquiry-based were assigned a " 0 ." An additional author coded 15\% of videos to establish inter-rater reliability. Any discrepancies in codes were discussed and resolved. Inter-rater reliability was established at 92\%. A two-way contingency table analysis was conducted to determine whether observed lessons from the SPD and TPD participants were equally likely to reflect inquiry-based instruction. The two variables were PD type (TPD, SPD) and the presence of inquiry (yes, no). Fisher's Exact Test was employed due to the small number of lesson observations.

\section{Final data analysis and interpretation}

This study took advantage of a variety of data sources to triangulate and support the validity of the findings. Final data interpretation occurred only after all quantifiable data had been collected and initially analyzed as described. This study approached data analysis and interpretation from the perspective that the quantitative data, while informative, was incomplete without participants' perspectives. Thus, qualitative interview data were used to help interpret patterns in other data sources and analyzed last.

\section{Results}

Study results are described in three sections that correspond to the research questions: (a) extent of use, (b) barriers, and (c) inquiry-based use.

\section{Extent of simulation use}

Significant differences in both reported frequency and confidence in simulation use prior to the PD (all p-values < .05) existed between TPD and SPD participants. Participants in the SPD reported greater confidence and frequency of simulation use 
Table 1. Self-reported simulation use frequency and confidence (pre-perceptions surveys).

\begin{tabular}{lccccc}
\hline & TPD M (SD) & SPD M (SD) & $d f$ & $t$ & Significance (2-tailed) \\
\hline Pre-PD frequency & $2.7(1.1)$ & $3.1(1.1)$ & 144.0 & -2.01 & $.046^{*}$ \\
Pre-PD confidence & $2.4(1.1)$ & $3.0(1.1)$ & 144.0 & -2.91 & $.044^{*}$ \\
\hline
\end{tabular}

Note. $1=$ never/not very confident; $5=$ very frequently/very confident.

$* p<.05$.

prior to the PD compared with TPD participants (Table 1). Initial reported confidence and frequency differences between the two groups were used to help interpret and discuss subsequent findings.

Observation reports documented simulation use by 22 of the $52(42.3 \%)$ TPD participants and 36 of the 104 (34.6\%) SPD participants. There was no difference in the percentage of TPD and SPD participants that used simulations following their respective PD modules, $\chi^{2}(1)=0.878, p=.349, \phi=-0.075$.

\section{Barriers to simulation use}

SPD participants experienced many barriers that may have limited their simulation use. The primary factor limiting simulation use was participant access to computers (Table 2). Participants explained that computer access in many schools was less than desirable and arranging access often required extensive future planning. Additionally, computer-based standardized testing restricted computer access throughout the academic year.

Table 2. Barriers to simulation use (SPD delayed post-perceptions survey responses, $n=67$ ).

\begin{tabular}{|c|c|c|}
\hline Barrier & Sample response & Number of participants (\%) \\
\hline $\begin{array}{l}\text { Insufficient computer } \\
\text { access }\end{array}$ & $\begin{array}{l}\text { We have } 90 \text { computers for use, but these computers are } \\
\text { shared by } 11 \text { classes. There was very limited time we } \\
\text { could sign up to use them (Sari). We have online } \\
\text { testing four times a year that takes up all computers } \\
\text { in the school for weeks at a time (Bobby). }\end{array}$ & $31(46.3 \%)$ \\
\hline $\begin{array}{l}\text { Software/ Internet } \\
\text { problems }\end{array}$ & $\begin{array}{l}\text { I did not use the simulations as much this year. One } \\
\text { reason was ... our student laptops did not have the } \\
\text { necessary software on them (Percy). The one and } \\
\text { only difficulty that I had was not being able to } \\
\text { connect to the Internet because there were not } \\
\text { enough hotspots in the school (Emma). }\end{array}$ & $11(16.4 \%)$ \\
\hline $\begin{array}{l}\text { Time constraints } \\
\text { (instructional or } \\
\text { planning) }\end{array}$ & $\begin{array}{l}\text { I only have } 45 \text { minutes every other week to teach } \\
\text { science (Lionel). I had a strong desire to use these } \\
\text { programs, just limited time in order to search to find } \\
\text { what was available (Corinne). }\end{array}$ & $9(13.4 \%)$ \\
\hline Effective PD & $\begin{array}{l}\text { Honestly, I did not feel that I had adequate training in } \\
\text { using the simulations-nor the time to teach it to } \\
\text { myself (Tara). }\end{array}$ & $5(7.5 \%)$ \\
\hline $\begin{array}{l}\text { Simulations not } \\
\text { age/content } \\
\text { appropriate }\end{array}$ & $\begin{array}{l}\text { I did not use computer simulations because there were } \\
\text { very few lessons applicable to the grade level I } \\
\text { taught. Almost all of the simulations were for the } \\
\text { upper grades (Trent). }\end{array}$ & $4(6.0 \%)$ \\
\hline $\begin{array}{l}\text { Instructional support } \\
\text { difficulties }\end{array}$ & $\begin{array}{l}\text { It is also sometimes frustrating to have students who } \\
\text { need such a large degree of assistance at times (Tico). }\end{array}$ & $4(6.0 \%)$ \\
\hline $\begin{array}{l}\text { School policy/ } \\
\text { administration }\end{array}$ & $\begin{array}{l}\text { The teachers were encouraged to utilize reading and } \\
\text { math activities during our lab period (Piper). }\end{array}$ & $2(3.0 \%)$ \\
\hline
\end{tabular}


Although computer access and software/IT considerations were the most common factors limiting simulation use, additional barriers existed. These barriers included insufficient planning and /or instructional time, limited participant confidence using simulations, instructional support challenges, and lack of age- and content-appropriate simulations.

Interview and observational data confirmed participant difficulties implementing simulations due to computer availability. For example, Carolyn explained, "Availability is really our biggest issue in doing computer simulations" (Interview). One reason teachers did not always have adequate computers was a result of computerized standardized tests. Phoebe explained she first used the tide-related Gizmo ${ }^{\circledR}$ and was excited to use additional simulations but, "then we didn't have the computers because they were pulled from the room for testing" (Interview). The burden of computerized benchmark and state-mandated testing on computer availability was apparent in several observed lessons. For example, Eve told her class,

We're going to be finishing up our [simulation] lab from yesterday. However, because of the benchmark schedule and availability of computers we're going to have to do the [simulation] lab in larger groups and at two stations to finish those up because I couldn't get another set of computers... So today we are going to have a [simulation] station at the SmartBoard ${ }^{\mathrm{TM}}$ and classroom computer. (Third observation)

As a result of limited computer access due to state-mandated testing Eve had to adjust her instructional plans.

Software and other computer-related challenges were apparent in lesson observations and discussed in interviews. For example, in one lesson, Gabe discovered student laptops were not updated with Shockwave ${ }^{\mathrm{TM}}$ that was needed for the simulation to work. Twenty minutes of instructional time was lost as Gabe updated student computers (Gabe, Third observation). Carolyn explained in her interview how outdated classroom computers further limited instructional technology incorporation. She explained,

The limited resources that we have and availability of computers because of online testing, also limits seven teachers in one grade level trying to use the computers effectively ... We have older computers that are in our classrooms. But we're, most of us, are down to two or three of them that are actually working and functioning. They are out of warrantee and we are working on budget issues trying to come up with a solution for how to get those computers back in classes. (Carolyn, Interview)

In Carolyn's experience, limited laptops, outdated technology, and online standardized test procedures all limited computer simulation implementation.

\section{Inquiry-based simulation use}

Of the 10 observed TPD lessons, four (40\%) reflected inquiry-based instruction. Of the 16 SPD observed lesson, 11 (68.8\%) involved inquiry-based instruction (Table 3). Fisher's Exact Test indicated there was no significant difference in the observed occurrence of inquiry instruction with simulations between the groups, $p=.228, \phi=0.283$. However, the medium effect size suggests the small number 
Table 3. Purpose of simulation use in observed lessons.

\begin{tabular}{llr}
\hline & \multicolumn{1}{c}{ Simulations used } & Inquiry-based lessons (\%) \\
\hline TPD observations $(n=10)$ & PhET (1), Tunes \& Spoons (1), Gizmo ${ }^{\circledR}(8)$ & $4(40 \%)$ \\
SPD observations $(n=16)$ & PhET (1), unidentified source (2), Gizmo ${ }^{\circledR}(13)$ & $11(68.8 \%)$ \\
\hline
\end{tabular}

of observations may have prevented sufficient power to detect differences between these two groups (Fan, 2001).

Although none of the SPD participants described a perceived benefit to the inquiry-based modeling that occurred during the PD, one participant from the TPD indicated modeling inquiry-based simulation use might have improved his own subsequent use:

I think it really helps when you work with teachers if you model things. So if there was an opportunity where all the teachers actually did some kind of exemplary lesson ... so you could kind of see that. (Tyson, Interview)

Based upon observation and interview data it is possible that modeling inquirybased simulation use during PD encouraged subsequent inquiry instruction.

\section{Summary}

In summary, there were no differences in the percentage of TPD and SPD participants that utilized simulations. In addition, there was no statistical difference in the occurrence of inquiry-based simulation use in the observed lessons. However, the small number of observations may have prevented the detection of differences. Although it appears the SPD did not yield greater benefits in terms of the measured variables, evidence suggests widespread barriers prevented simulation use in many of the schools.

\section{Discussion}

This study examined whether modeling simulation use for inquiry instruction and providing participants opportunities for practice and lesson planning within a collaborative PD setting influenced participants' simulation use. Participation in an SPD community first as learners and subsequently as teachers under the guidance of PD implementers was expected to lead to greater simulation adoption and more inquiry-based simulation use. The results indicate that while an SPD may facilitate inquiry-based use, there may be a soft ceiling to adoption as a result of integration barriers that an SPD may not easily overcome.

Research findings did not support the hypothesis that the SPD would increase the percentage of participants that used simulations. The similar frequency of simulation use between the groups suggests that, even though SPD implementers provided content-relevant, collaborative, lesson planning time, these additional elements were insufficient to yield major changes in the percentage of participants that would adopt the new technology. These findings are inconsistent with previous 
study outcomes (Gerard et al., 2011; Ketelhut \& Schifter, 2011; Pope, Jayroe, Franz, \& Hamil, 2008). However, widespread integration barriers coupled with higher selfreported initial simulation use by SPD participants could have prevented the benefits of the SPD from being realized.

Previous ET research has widely noted barriers to integration (Gerard et al., 2011; Pennell \& Ewing-Taylor, 2012; Zhao \& Bryant, 2006). Although the results of this study support several others indicating technology access is the most common integration barrier (Gerard et al., 2011; Pennell \& Ewing-Taylor, 2012; Zhao \& Bryant, 2006), limited participant computer access was sometimes attributed to computerized, state-mandated testing procedures rather than actual lack of physical computers or funding as previously documented (Gerard et al., 2011; Pennell \& EwingTaylor, 2012; Zhao \& Bryant, 2006). Computerized testing required some teachers to change their lesson plans on the day of instruction. In other cases, teachers had to plan weeks ahead to ensure access to computers. While interview and observation evidence suggested that some participants could adapt to unexpected daily changes in computer availability to carry through with planned simulation use, other participants were unable or not sufficiently motivated to and therefore did not use simulations as extensively as they otherwise would have.

Participants also reported a host of additional computer-related barriers including outdated software, lack of Internet connectivity, and insufficient technical support to overcome integration barriers. This finding may reflect the inconsistent job responsibilities and extent of teacher support provided by technology support personnel (Ronnkvist, Dexter, \& Anderson, 2000; Staples, Pugach, \& Himes, 2005). The data presented in this study suggest technology support personnel are either not readily available to all participants or may not have the skills to help teachers troubleshoot technology integration challenges related to computer software, hardware, and Internet connectivity.

The statistical analysis of the frequency of inquiry-based instruction in each cohort was inconclusive. Although Fishers Exact Test was insignificant, the medium effect size indicates this result should be interpreted with caution. With only a handful of observations, it is possible that there was insufficient power to discern differences. Interview data indicated participants in the TPD would have valued and felt more prepared to use simulations during instruction if they had experienced a modeled inquiry lesson. Thus, the addition of the inquiry-based model lesson in the SPD may have provided participants an exemplar lesson from which to design future ones.

\section{Limitations and future research}

Limitations to the study influenced the breadth of conclusions that could be made and provide avenues for future research. Although there were no detectable differences in the extent of simulation use between SPD and TPD participants, the validity of this finding would be strengthened if triangulated with additional data sources. The percentage of each cohort that used simulations was based on 
observation reports that only captured four weeks of science instruction. Thus, we recommend future research consider using surveys to also document and triangulate participants' extent of simulation use.

Conclusions about the effectiveness of the SPD in promoting inquiry-based simulation use are difficult to reach for two reasons. First, the greater self-reported initial confidence and frequency of simulation use among participants in the SPD may have influenced study outcomes. Prior research has demonstrated that it takes time for teachers to use technology for more student-centered instruction following technology adoption (Schnittka \& Bell, 2010; Meskill et al., 2002). Thus, if more participants in the SPD already had familiarity with simulations, inquiry-based use may be a natural pedagogical progression. In addition, the small number of lesson observations may have prevented discernible differences in inquiry-based use between the SPD and TPD participants. Before conclusions can be made about the effectiveness of situated versus more technically oriented simulation PD programs, the study should be replicated with more similar participant groups and include more lesson observations.

The findings of the study raise additional questions for future investigations. Ongoing coaching is an important component of situated learning theory that was not examined in this study. Coaches and peers may be able to help participants overcome technology integration barriers. In addition, the extent technology personnel are prepared to or enabled to support teachers in their everyday technology integration challenges should be documented to inform avenues for continued school improvement.

In the current study, participants ranged in teaching experience from none to 38 years, and it is likely participants' technology experience varied as well. These participant differences were not accounted for during data analysis and future research should explore how technology PD may differentially impact novice and experienced teachers. For example, while the PD was adequate in equipping many participants with the skills needed to implement simulations, it may have needed to be more extensive for participants with less experience with technology in general and simulations in particular.

Finally, barriers to simulation use were described in interviews and open-ended survey responses. Participants often referenced insufficient computer access without elaboration. As a result, the extent to which computer-based standardized tests was the underlying problem is unknown. It would be valuable to determine how widespread this integration barrier is.

\section{Implications}

The findings of the present study have implications for policy makers, school administrators, and PD designers and implementers. The potential benefits of the SPD that might have led to increased simulation use may not have been realized for two primary reasons. First, the instructional context that many teachers returned to presented widespread simulation integration barriers that effectively terminated 
the learning progress begun in the SPD program. Although the number of available computers in schools has risen (National Center for Education Statistics [NCES], 2011), it appears that in many schools, computers are being monopolized for standardized test taking procedures and are not available for instructional use. Second, participants found the personnel, infrastructure, and computer programs that comprise software (Rogers, 2003) to be inadequate to support their instructional simulation use efforts. In addition to making sure adequate hardware exists, additional attention needs to be given to software, including the preparation and availability of technology support specialists in schools. PD implementers should help participants identify possible simulation implementation barriers and provide avenues to troubleshoot. Teacher PD needs to not only equip participants with new pedagogical strategies, but also help provide means to use them within participants' instructional contexts.

\section{Conclusion}

Situated learning theory explains how communities with unique principles, traditions, and skills perpetuate (Lave \& Wenger, 1991). As long as novices have scaffolded opportunities to acquire and practice applying new knowledge and skills, communities persist (Lave \& Wenger, 1991). School conditions that prevent or limit simulation implementation create educational contexts that potentially prevent skill and knowledge transfer from scientific communities to K-12 science students. Simulations provide students opportunities to engage in scientific inquiry (Trundle \& Bell, 2010; Hilton \& Honey, 2011), master scientific concepts (Dega et al., 2013; Zacharia, 2007), and use technology in scientific ways (Medina \& Mauk, 2000; Nada \& Furukawa, 2012). Without access to computers and the software to support simulation use, science teachers cannot cultivate scientifically and technologically literate students. Therefore, the propagation of scientific communities becomes difficult and may partially explain why so many students are unprepared to pursue science, technology, engineering, and mathematics (STEM) degrees and careers (Arastoopour, Chesler, \& Shaffer, 2014). In light of these trends and the importance of technology-supported inquiry-based science education, we urge administrators to address the monopolization of computer resources for computerized standardized tests and overwhelming software-related challenges the participants in the current study indicated limited or prevented instructional simulation use.

\section{References}

Arastoopour, G., Chesler, N. C., \& Shaffer, D. W. (2014). Epistemic persistence: A simulationbased approach to increasing participation of women in engineering. Journal of Women and Minorities in Science and Engineering, 20(3), 211-234.

Bell, R. L., Maeng, J. L., \& Binns, I. C. (2013). Learning in context: Technology integration in a teacher preparation program informed by situated learning theory. Journal of Research in Science Teaching, 50, 348-379.

Bell, R. L., Smetana, L., \& Binns, I. (2005). Simplifying inquiry instruction. The Science Teacher, 72(7), 30-33. 
Bell, R. L., \& Trundle, K. C. (2008). The use of a computer simulation to promote scientific conceptions of moon phases. Journal of Research in Science Teaching, 3, 346-372

Berliner, D. C. (2001). Learning about and learning from expert teachers. International Journal of Educational Research, 35, 463-482.

Brown, J. S., Collins, A., \& Duguid, P. (1989). Situated cognition and the culture of learning. Educational Researcher, 18, 32-42.

Chang, H., \& Linn, M. C. (2013). Scaffolding learning from molecular visualizations. Journal of Research in Science Teaching, 50, 858-886.

Dega, B. G., Kriek, J., \& Mogese, T. F. (2013). Students conceptual change in electricity and magnetism using simulations: A comparison of cognitive perturbation and cognitive conflict. Journal of Research in Science Teaching, 50, 677-698.

Donnelly, D. F., Linn, M. C., \& Ludvigsen, S. (2014). Impacts and characteristics of computerbased science inquiry learning environments for precollege students. Review of Educational Research, 84, 572-608.

Fan, X. (2001). Statistical significance and effect size in education research: Two sides of a coin. Journal of Educational Research, 94, 275-282.

Finkelstein, N. D., Adams, W. K., Keller, C. J., Kohl, P. B., Perkins, K. K., Podolofsky, N. S., \& Reid, S. (2005). When learning about the real world is better done virtually: A study of substituting computer simulations for laboratory equipment. Physical Review Special TopicsPhysics Education Research, 1(010103), 1-8.

Gerard, L. F., Varma, K., Corliss, S. B., \& Linn, M. C. (2011). Professional development for technology-enhanced inquiry science. Review of Educational Research, 81, 408-448.

Gibson, H. L., \& Chase, C. (2002). Longitudinal impact of an inquiry-based science program on middle school students' attitudes towards science. Science Education, 86, 693-705.

Gonczi, A. L. (May, 2015). Professional development and teachers' pedagogical content knowledge: Factors influencing science education computer simulation use. (Unpublished doctoral dissertation). University of Virginia, Charlottesville, VA.

Graham, C. R., Burgoyne, N., Cantrell, P., Smith L., St. Clair., L., \& Harris, R. (2009). TPACK development in science teaching: Measuring the TPACK confidence of inservice science teachers. TechTrends, 53(5), 70-79.

Guzey, S. S., \& Roehrig, G. H. (2009). Teaching science with technology: Case studies of science teachers' development of technology, pedagogy, and content knowledge. Contemporary Issues in Technology and Teacher Education, 9, 25-45.

Hennessy, S., Deaney, R., \& Ruthven, K. (2006). Situated expertise in integrating use of multimedia simulation into secondary science teaching. International Journal of Science Education, $28,701-732$.

Hennessy, S., Wishart, J., Whitelock, D., Deaney, R., Brawn, R., Velle, L. L., ... Winterbottom, M. (2007). Pedagogical approaches for technology-integrated science teaching. Computers \& Education, 48(1), 137-152.

Hesse-Biber, S. N. (2010). Mixed methods research: Merging methods with practice. New York, NY: Guilford Press.

Higgins, T. E., \& Spitulnik, M. W. (2008). Supporting teachers' use of technology in science instruction through professional development: A literature review. Journal of Science Education and Technology, 17, 51-521.

Hilton, M., \& Honey, M. A. (Eds.). (2011). Learning science through computer games and simulations. Washington, DC: National Academies Press.

International Society for Technology in Education (ISTE). (2008). National technology education standards for teachers (2nd ed.). Eugene, OR: Author.

Jimoyiannis, A. (2010, June). Developing a technological pedagogical content knowledge framework for science education: Implications of a teacher trainers' preparation program. Proceedings of Informing Science \& IT Education Conference (InSITE), 2, 597-607. Cassino, Italy. 
Ketelhut, D. J., \& Schifter, C. C. (2011). Teachers and game-based learning: Improving understanding of how to increase efficacy of adoption. Computers \& Education, 56, 529-546.

Lave, J., \& Wenger, E. (1991). Situated learning: Legitimate peripheral participation. Cambridge, NY: University of Cambridge Press.

Lawless, K. A., \& Pellegrino, J. W. (2007). Professional development in integrating technology into teaching and learning: Knowns, unknowns, and ways to pursue better questions and answers. Review of Educational Research, 77, 575-614.

Luft, J. A., \& Hewson, P. W. (2014). Research on teacher professional development programs in science. Handbook of Research in Science Education, 2, 889-909.

Maeng, J. L., Mulvey, B. K., Smetana, L. K., \& Bell, R. L. (2013). Preservice teachers' TPACK: Using technology to support inquiry instruction. Journal of Science Education and Technology, 22(6), 838-857.

Marshall, J. A., \& Young, E. S. (2006). Preservice teachers' theory development in physical and simulated environments. Journal of Research in Science Teaching, 43, 907-937.

Medina, J. F., \& Mauk, M. D. (2000). Computer simulation of cerebellar information processing. Nature Neuroscience, 3, 1205-1211.

Meskill, C., Mossop, J., DiAngelo, S., \& Pasquale, R. K. (2002). Expert and novice teachers talking technology: Precepts, concepts, and misconcepts. Language Learning \& Technology, 6(3), 46-57.

Morrison, J. A. (2013). Exploring exemplary elementary teachers' conceptions and implementation of inquiry science. Journal of Science Teaching \& Education, 24, 573-588.

Nada, H., \& Furukawa, Y. (2012). Antifreeze proteins: Computer simulation studies on the mechanism of ice growth inhibition. Polymer Journal, 44, 690-698.

National Center for Education Statistics (NCES). (2011). Table 109: Number and Internet access of instructional computers and rooms in public schools, by selected school characteristics. Digest of Education Statistics. Washington, DC: U.S. Department of Education. Retrieved from nces.ed.gov.

National Research Council (NRC). (2012). A framework for K-12 science instruction. Washington, DC: National Academy Press.

Pennell, S., \& Ewing-Taylor, J. (2012, March). 21st century learning and teaching through integrating technology into inquiry-based professional development. Proceedings of Society for Information Technology \& Teacher, 2012(1), 2055-2060, Austin, TX.

President's Council of Advisors on Science and Technology. (2010). Report to the President prepare and inspire: K-12 education in science, technology, engineering, and math (STEM) for America's future. Washington, DC: Government Printing Office. Retrieved from http://www.whitehouse.gov/administration/eop/ostp/pcast/docsreports

Plass, J. L., Milne, C., Homer, D., Schwartz, R. N., Hayward, E. O., Jordan, T., ... Barrientos, J. (2012). Investigating the effectiveness of computer simulations for chemistry learning. Journal of Research in Science Teaching, 49, 394-419.

Podolefsky, N. S., Perkins, K. K., \& Adams, W. K. (2010). Factors promoting engaged exploration with computer simulations. Physics Education Research, 6, 1-8.

Pope, M., Jayroe, T., Franz, D., \& Hamil, B. (2008). Teacher candidates and technology: Making integration happen. National Forum of Applied Educational Research Journal, 21(3), 1-9.

Pyatt, K., \& Sims, R. (2012). Virtual and physical experimentation in inquiry-based science labs: Attitudes, performance and access. Journal of Science Education and Technology, 21, 133-147.

Rogers, E. M. (2003). Diffusion of innovations (5th ed.). New York, NY: Free Press.

Ronnkvist, A. M., Dexter, S. L., Anderson, R. E. (2000). Technology support: It's depth, breadth, and impact in America's schools. Teaching, learning, and computing [1998 National Survey Report \#5]. Irvine, CA: Center for Research on Information Technology and Organizations, University of California, Irvine. Retrieved from http://www.crito.uci.edu/tlc/findings/technology-suppport/ 
Russell, G., \& Bradley, G. (1997). Teachers' computer anxiety: Implications for professional development. Education and Information Technologies, 2(1), 17-30.

Ryoo, K., \& Linn, M. C. (2012). Can dynamic visualizations improve middle school students' understanding of energy in photosynthesis? Journal of Research in Science Teaching, 49, 218-243.

Schnittka, C., \& Bell, R. L. (2009). Preservice biology teachers' use of interactive display systems to support reforms-based science instruction. Contemporary Issues in Technology and Teacher Education, 9(2), 131-159.

Staples, A., Pugachm, M. C., \& Himes, D. (2005). Rethinking the technology integration challenge: Cases from three urban elementary schools. Journal of Research on Technology in Education, 37, 285-311.

Tamim, R. M., Bernard, R. M., Borokhovski, E., Abrami, P. C., \& Schmid, R. F. (2011). What forty years of research says about the impact of technology on learning: A second-order metaanalysis and validation study. Review of Educational Research, 81, 4-28.

Trundle, K., \& Bell, R. (2010). The use of a computer simulation to promote conceptual change: A quasi-experimental study. Computers \& Education, 54, 1078-1088.

Waight, N., \& Abd-El-Khalick, F. (2007). The impact of technology on the enactment of "inquiry" in a technology enthusiast's sixth grade science classroom. Journal of Research in Science Teaching, 44, 154-182.

Walker, A., Recker, M., Ye, L., Robertshaw, M. R., Sellers, L., \& Leary, H. (2012).Comparing technology-related teacher professional development designs: A multilevel study of teacher and student impacts. Education Technology Research Development, 60, 421-444.

Zacharia, Z. C. (2007). Comparing and combining real and virtual experimentation: An effort to enhance students' conceptual understanding of electric circuits. Journal of Computer Assisted Learning, 23, 120-132.

Zhao, Y., \& Bryant, F. L. (2006). Can teacher technology integration training alone lead to high levels of technology integration? A qualitative look at teachers' technology integration after state mandated technology training. Electronic Journal for the Integration of Technology in Education, 5(1), 53-62.

\section{Appendix A}

Interview Protocol (Instructional Computer Simulation Implementation) Topic 1: Experience and Method of Simulation Use by Teachers

1. Tell me about your experiences using simulations.

2. Describe how you incorporate a simulation into a lesson. Probes: Do you have students use the simulation before introducing the subject matter or afterwards? Do you use handouts or other supplementary materials to guide them through the simulations? If so, where have these supplemental materials come from? Do you use one computer/projector to give whole class instruction or do students work individually or in groups/pairs?

3. What are some of the simulations you have used? How was this related to the content/skills you were teaching? Describe the content or skills you were trying to teach with these simulations.

4. What are some of the advantages or disadvantages you have found to using simulations? Probes: In what ways have they affected the content you teach? In what ways have they affected the science skills you teach? Are there any instances in which access to technology has been a challenge? 
Topic 2: Interactions

1. Describe your role when students are using a simulation. Probes: What sorts of comments might you make to students? How often do you visit a student using a simulation? Describe the amount of and type of support/guidance you give individual students or the class. How is this support similar and/or different from the support you provide during hands-on labs? Describe any help students have needed using the screen interface

2. Describe some of the responses students have had to using simulations. Probes: Describe any evidence you have that students have enjoyed using them. Describe any evidence you have that students have not enjoyed them. Evidence of frustration? Evidence that they are not on task?

3. How would you characterize the impact of the simulations with regard to helping student learning? Describe any evidence you have that simulations were not successful in helping students learn the intended content/skills. Probes: Describe comments students made that indicated understanding or lack thereof? Describe instances when students asked classmates for help? How did assessments indicate understanding/or lack of understanding of content/skills?

Topic 3: Context of Simulation Use

1. If you have used a simulation to support an inquiry-based lesson, describe how the simulation was included. Why would you say this was an inquirybased lesson?

2. If you have used a simulation within a problem-based learning unit, describe the unit and how the simulation was used. Why would you say this was a problem-based unit?

Topic 4: Factors Affecting Simulation Use

1. What are some of the reasons you would use one simulation instead of a different available computer simulation? Why do you choose to use a simulation during science instruction instead of a hands-on lab?

2. Describe any factors that would make you more likely to use more simulations in future lessons. Probes: Describe any recommendations you have for further PD? How would you like that training to occur (where, duration, content)? Would changes in access to computer technology change your use of computer simulations?

\section{Appendix B}

Classroom Observation Protocol

Section I. Background Information

Observer: Observation \# (bold one): 1234

Teacher Name: School:

Grade Level/Content Area:

Date: Start Time: End Time:

Total number of students in class:

Section II. Contextual Background 
Ask teacher before observing:

A. Objective(s) for lesson:

B. How does lesson fit in the current context of instruction? (e.g., connection to previous and other lessons. What topics/activities/lessons occurred in the three science lessons prior to this lesson? What topics/activities/lessons will be covered in the three science lessons following this lesson?) All blanks should be completed and answers should be based on the teacher's interpretation of the lesson, not the coach's.

$\mathrm{Y}=$ yes, the lesson includes this criterion, $\mathrm{N}=$ no, the lesson does not include this criterion, $\mathrm{DK}=$ participant indicates he or she does not know what the criteria mean or whether the lesson meets the criteria

\begin{tabular}{llllllll}
\hline \multicolumn{3}{c}{ Days preceding } & & \multicolumn{3}{c}{ Days following } \\
\cline { 2 - 3 } \cline { 5 - 7 } & & & Doday & & Day 1 & Day 2 & Day 3 \\
\hline
\end{tabular}

Topic(s)

Activities

Problem-based learning (PBL)?

Nature of science (NOS)?

Inquiry?

Technology?

Note: If you indicated "yes" for PBL, NOS, Inquiry, Tech briefly describe below what made it (why you think it is) a $\mathrm{PBL} / \mathrm{NOS} / \mathrm{Inq} / \mathrm{Tech}$ lesson.

C. Classroom setting. Describe anything about the classroom layout that would constrain the teaching of science.

D. Other relevant details about the time, day, students, or teacher that you think are important? (i.e., teacher bad day, day before spring break, pep rally previous hour, etc.)

Section III. Description of Events Over Time (indicate time when the activity changes). (You may complete this section or include the notes you took on this lesson.) Make sure that you describe the activity.

Please attach any other documentation from the classroom observation. 